Tropical Journal of Pharmaceutical Research October 2011; 10 (5): 655-661

(C) Pharmacotherapy Group,

Faculty of Pharmacy, University of Benin

Benin City, 300001 Nigeria.

All rights reserved.

Available online at http://www.tjpr.org

Research Article

http://dx.doi.org/10.4314/tjpr.v10i5.15

\title{
Development of a New RP-UPLC Method for the Determination of Rabeprazole Sodium in Pharmaceutical Formulation and Application in Dissolution Studies
}

\author{
$\mathrm{K}_{\text {Karunakaran }}{ }^{1^{\star}}$, G Navaneethan ${ }^{1}$ and KP Elango ${ }^{2}$ \\ ${ }^{1}$ Department of Chemistry, Sona College of Technology, Anna University, Salem 636 005, ${ }^{2}$ Department of \\ Chemistry, Gandhigram Rural Institute, Deemed University, Gandhigram 624302, India
}

\begin{abstract}
Purpose: To develop a reverse phase ultra-performance liquid chromatographic (RP-UPLC) method for the estimation of rabeprazole sodium in tablet formulations.

Methods: Chromatographic separation was achieved on a Waters Acquity BEH $C_{18}(50 \times 2.1 \mathrm{~mm}$, particle size $1.7 \mu \mathrm{m}$ ) column using an isocratic method with mobile phase composed of acetonitrile and phosphate buffer $(\mathrm{pH} 7.4)$ in the ratio of 35:65 ( $/ \mathrm{v})$. The flow rate was $0.4 \mathrm{ml} / \mathrm{min}$, temperature of the column was maintained at ambient, injection volume was $5 \mu \mathrm{L}$ and detection was made at $280 \mathrm{~nm}$. The run time was as short as 2 min. Comparison of system performance with conventional HPLC was made with respect to analysis time, efficiency and sensitivity.

Results: The developed method was linear for rabeprazole sodium from $0.03-30 \mu \mathrm{g} / \mathrm{ml}$ and the linear regression obtained was $>0.999$. Precision, evaluated by intra- and inter-day assay,s had relative standard deviation (R.S.D) values within $1.5 \%$. Recovery data were in the range $98.0-101.5 \%$ with R.S.D. values $<1.5 \%$.

Conclusion: The method is precise, accurate, linear, robust and fast. The short retention time of 1.49 min allows the analysis of a large number of samples in a short period of time and, therefore, should be cost-effective for routine analysis in the pharmaceutical industry.
\end{abstract}

Keywords: Ultra performance liquid chromatography, Assay, Rabeprazole sodium, Validation 


\section{INTRODUCTION}

Rabeprazole sodium (RAB) is a proton pump inhibitor with actions and uses similar to those of omeprazole. It is given orally as enteric coated rabeprazole tablets and normally taken in the morning. In the treatment of severe ulcerative gastrooesophogeal reflux desease, the usual dose is $20 \mathrm{mg}$ once daily for 4 to 8 weeks; in the USA, a further 8-week course is permitted for healing of erosive oeophogistis [1]. Chemically rabeprazole is $2-[\{(4) 3-$ methoxypropoxy-3-methyl-2-pyridinyl\} sulphinyl\} $1-\mathrm{H}$ benzimidazole; its structure is shown in Fig 1.

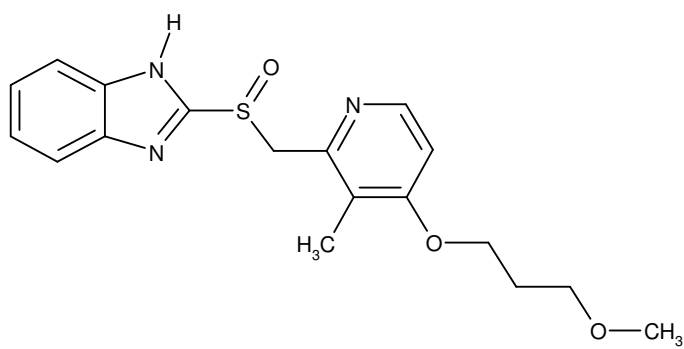

Fig 1: Structure of rabeprazole

Methods that have been reported for the determination of RAB include HPLC [2-5], thin layer chromatography (TLC) [6], UV spectrophotometry [7-9] and voltametry [10]. A method has been reported for the determination of the enantiomer and metabolite of RAB using HPLC [11] while some methods have also been published for the quantitative analysis of RAB in combination with other drugs [12-15].

Ultra performance liquid chromatography (UPLC) is an emerging liquid chromatography technique which enables significant reduction in run time and solvent consumption. To the best of our knowledge, no UPLC method has been reported yet for the determination of RAB in pharmaceutical formulations.

The aim of the present study was to develop a simple UPLC method for the determination of $\mathrm{RAB}$ in tablets and compare the results with those of HPLC.

\section{EXPERIMENTAL}

\section{Chemicals and reagents}

Rabeprazole sodium (RAB) was received as a gift from Metro Labs Ltd, Baddi, India. RAB tablets was purchased from a local pharmacy. (Pepraz ${ }^{\circledR}, 10 \mathrm{mg}$, East West Pharma, India). HPLC grade acetonitrile was purchased from Merck India Ltd, Mumbai, India. High purity water was obtained using Millipore Milli-Q water purification system (Billerica, MA, USA). All other reagents were of analytical grade.

\section{Instrumentation and operating conditions}

The HPLC system used for initial chromatographic development was a Waters Alliance separation module with 2487 UV detector. A Waters symmetry $\mathrm{C}_{18}$ column $(150 \times 4.6 \mathrm{~mm}$, particle size $5 \mu \mathrm{m})$ was used for separation. The mobile phase consisted of a mixture of phosphate buffer $(\mathrm{pH} \mathrm{7.4)}$ and acetonitrile in the ratio 65:35 (v/v). The flow rate was $1.0 \mathrm{ml} / \mathrm{min}$ while the injection volume was $20 \mu \mathrm{L}$ and detection was at 280 $\mathrm{nm}$. The column temperature was maintained at ambient.

UPLC analysis was performed on a Waters Acquity UPLC system (Milford, USA) equipped with a binary solvent manager, an auto sampler, and a column manager composed of a column oven and tunable ultra violet (tuv) detector. Chromatographic separation was performed using a Waters Acquity $\mathrm{BEH} \mathrm{C}_{18}(50 \times 2.1$ $\mathrm{mm}$, particle size $1.7 \mu \mathrm{m}$ ) column with the column temperature maintained at ambient while the mobile phase was the same as that used for HPLC. Flow rate was $0.4 \mathrm{ml} / \mathrm{min}$ and the detector was set at $280 \mathrm{~nm}$. Data acquisition, handling and instrument control 
were performed with the aid of Empower software, version 1.0.

\section{Preparation of standards}

A stock solution of $1.0 \mathrm{mg} / \mathrm{ml}$ was prepared by dissolving an appropriate amount of RAB in $10 \mathrm{mM}$ potassium hydroxide solution. $A$ working solution of $10 \mu \mathrm{g} / \mathrm{ml}$ was prepared from this stock solution by serial dilution.

\section{Preparation of test solution from tablets}

Twenty tablets were weighed and powdered. An amount of the powder equivalent to $50 \mathrm{mg}$ of RAB was taken into a $100 \mathrm{~mL}$ volumetric flask, and extracted with $10 \mathrm{mM}$ potassium hydroxide solution for $10 \mathrm{~min}$. The solution was diluted suitably to $10 \mu \mathrm{g} / \mathrm{ml}$ and filtered through a $0.45 \mu \mathrm{m}$ Millipore nylon filter paper.

\section{Dissolution sample preparation}

Labindia 2000 dissolution apparatus (a sixtablets dissolution unit) (Labindia, Mumbai, India) was used to test the dissolution of the tablets and hence generate test samples for analysis using the developed method. The dissolution test followed the procedure stipulated by United States Pharmacopoeia (USP) using apparatus 2 with paddles. The paddle speed was $100 \mathrm{rpm}$ and the dissolution conditions followed US FDA (United States Food and Drug Administration) recommendation; the dissolution temperature of the media was maintained $37.0 \pm 0.5^{\circ} \mathrm{C}$. For delayed release RAB tablets, the US FDA recommends dissolution test in $700 \mathrm{~mL}$ of $0.1 \mathrm{~N} \mathrm{HCl}$ for $2 \mathrm{~h}$ (samples were collected at intervals for assay of RAB), after which $300 \mathrm{~mL}$ of $0.6 \mathrm{M}$ Tris- $\mathrm{HCl}$ buffer $(\mathrm{pH} \mathrm{8.0)}$ was added to the medium and the dissolution test continued for $45 \mathrm{~min}$, during which samples were also withdrawn at intervals for assay of $\mathrm{RAB})$. Auto sampling was used to collect samples $(10 \mathrm{ml})$ at intervals over the test period. The samples were immediately filtered through a $0.45 \mu \mathrm{m}$ Millipore nylon filter. The first $2 \mathrm{ml}$ of the sample obtained each time during filtration was discarded in order to clean out the filter paper and thus maintain uniform filtration.

\section{Method validation}

\section{System suitability}

Standard solution was used for the system suitability check. System suitability was analysed in terms of USP tailing factor ( $\leq$ $2.0)$, theoretical plate counts $(\geq 30000)$ and $\%$ R.S.D. (relative standard deviation) for five replicate injections (should be $\leq 2.0$ ).

\section{Precision}

The precision of the method was evaluated by carrying out six independent assays of RAB test (tablet) sample against a qualified reference standard and the \% R.S.D. of assay was calculated. The intermediate precision of the method was also evaluated using a different analyst, different columns of the same brand (Waters Acquity, $\mathrm{BEH} \mathrm{C}_{18}$, $50 \times 2.1 \mathrm{~mm}$, particle size $1.7 \mu \mathrm{m})$ and instrument (UPLC system, Waters Acquity) in the same laboratory.

\section{Limits of detection (LOD) and quantification (LOQ)}

LOD and $L O Q$ for RAB were determined at signal-to-noise ratios of $3: 1$ and $10: 1$, respectively, by injecting series of dilute solution with known concentrations. Precision evaluation was also carried out at the LOQ level by injecting six individual preparations, and calculating the \% RSD of the area.

\section{Linearity}

Test solutions were prepared from RAB stock solution at ten concentration levels from LOQ to $300 \%$ of analyte concentration $(0.03,0.5$, $1.0,5.0,7.5,10.0,12.5,15.0,20.0$ and 30.0 $\mu \mathrm{g} / \mathrm{ml})$. The peak area versus concentration data was treated by least squares linear regression analysis. 


\section{Accuracy}

The accuracy of the assay method was evaluated in triplicate at six concentration levels (between 10 and $150 \%$ ), i.e., 1.0, 3.0, 5.0, 7.5, 10.0, and $15.0 \mu \mathrm{g} / \mathrm{ml}$. Percent recoveries were calculated.

\section{Robustness}

To determine the robustness of the developed method, experimental conditions were deliberately altered, and system suitability parameters were checked. The flow rate of the mobile phase was $0.4 \mathrm{ml} / \mathrm{min}$. To study the effect of flow rate, flow rate was changed by 0.05 units from 0.35 to 0.45 $\mathrm{ml} / \mathrm{min}$, the proportion of acetonitrile in the mobile phase $35 \%$ was changed by $\pm 3.5 \%$, and UV detection wavelength $(280 \mathrm{~nm})$ was changed $\pm 3 \mathrm{~nm}$. To study the effect of $\mathrm{pH}$ variation in the mobile phase, $\mathrm{pH}$ was altered by \pm 0.2 units, i.e., to 7.2 and 7.6. Changes in chromatographic parameters, i.e., theoretical plates, tailing factor and \% R.S.D. were evaluated for the method.

\section{RESULTS}

\section{Method validation}

Based on International Conference on Harmonization (ICH) guidelines [16], the method is validated with regard to system suitability, linearity, accuracy, precision, LOD, $\mathrm{LOQ}$ and robustness as follows.

\section{System suitability}

The system suitability results for the proposed UPLC method are given in Table 1. The results proves that the optimized UPLC method fulfils these requirements within the USP accepted limits indicated in the 'Experimental' section.

\section{Precision}

The \% R.S.D. of RAB assay during the method precision and the intermediate precision was 1.3 and 1.1 , respectively, indicating good precision of the method.

Table 1: System suitability results

\begin{tabular}{|c|c|c|c|c|}
\hline Injection & $\mathbf{R T}^{*}$ & $\begin{array}{l}\text { Peak } \\
\text { area }\end{array}$ & $\begin{array}{l}\text { USP } \\
\text { tailing }\end{array}$ & $\begin{array}{c}\text { USP } \\
\text { theoretical } \\
\text { plates }\end{array}$ \\
\hline 1 & 1.492 & 7019896 & 1.21 & 44222 \\
\hline 2 & 1.491 & 7102321 & 1.19 & 45151 \\
\hline 3 & 1.487 & 7082325 & 1.20 & 45132 \\
\hline 4 & 1.493 & 7095331 & 1.19 & 44125 \\
\hline 5 & 1.472 & 7152345 & 1.22 & 45321 \\
\hline Mean & 1.487 & 7090444 & 1.20 & 44790 \\
\hline \% R.S.D & 0.58 & 0.67 & 1.08 & 1.27 \\
\hline
\end{tabular}

${ }^{\star} R T=$ retention time

Limits of detection (LOD) and quantification (LOQ)

LOD and LOQ for RAB were 0.007 and 0.03 $\mu \mathrm{g} / \mathrm{ml}$, respectively. The LOQ R.S.D. for the six preparations was $3.2 \%$, confirming the high precision of the $\mathrm{LOQ}$ at $0.03 \mu \mathrm{g} / \mathrm{ml}$. Since the $L O Q$ and $L O D$ values of $R A B$ are achieved at a very low level, this method can be suitable for cleaning validation in the pharmaceutical industry.

\section{Linearity}

The linearity of the calibration plot for the method was obtained over the calibration ranges tested, i.e., $0.03-30 \mu \mathrm{g} / \mathrm{ml}$, and the correlation coefficient obtained was $>0.999$, thus indicating excellent correlation between peak areas and concentrations of the analyte. The regression equation is $\mathrm{Y}_{\mathrm{RAB}}=705304 \mathrm{x}$ $23709\left(r^{2}=0.9999\right)$.

\section{Accuracy}

Percent recovery of RAB samples ranged from 98.0 to 101.5 , and \% R.S.D. values were within $1.3 \%$, showing the good accuracy of the method. The result is shown in Table 2.

Trop J Pharm Res, October 2011;10(5):658 


\section{Robustness}

In all the deliberately varied chromatographic conditions, the assay results was between 98 and $101 \%$ and no significant changes were obtained in chromatographic parameters. This shows the robustness of the developed method.

Table 2: Recovery data

\begin{tabular}{cccc}
\hline $\begin{array}{c}\text { Amount added } \\
\text { Level } \\
\text { Concentration } \\
\text { (in } \boldsymbol{\mu g} / \mathbf{m l})\end{array}$ & $\begin{array}{c}\% \\
\text { Recovery } \\
(\mathbf{n}=\mathbf{3})\end{array}$ & $\begin{array}{c}\text { R.S.D } \\
(\mathbf{n}=3)\end{array}$ \\
\hline 10 & 1.0 & 99.3 & 0.5 \\
30 & 3.0 & 100.9 & 1.1 \\
50 & 5.0 & 98.0 & 0.8 \\
75 & 7.5 & 99.5 & 1.3 \\
100 & 10.0 & 101.5 & 0.9 \\
150 & 150 & 99.2 & 1.2 \\
\hline
\end{tabular}

Application of the developed method to commercial RAB tablets

When the developed method was used to analyze a commercial brand of RAB tablet formulation, the mean recovery of six replicates was $99.69 \%$ with \% R.S.D. of 0.52 . The $\%$ recovery value indicates noninterference from the excipients present in the dosage form.

Application of the developed method to withdrawn RAB tablet dissolution samples indicates that mean release in acid $(\mathrm{pH} 1.2)$ mediun was $2.8 \%(n=6))$ with \% R.S.D of 4.5 and while in alkaline medium $(\mathrm{pH} 8.0$ buffer), the release was $97.2 \%(n=6)$ with \% R.S.D of 3.2 .

Both the assay and dissolution test analyses were performed within 45 min thus indicating rapidity of analysis using UPLC method.

\section{DISCUSSION}

\section{Method development and optimization}

The main aim of the developed method was to achieve separation and quantification of $\mathrm{RAB}$ using an isocratic mobile phase with
UPLC system. Developing a UPLC method was to reduce the run time of the method and solvent consumption for routine analysis such as assay, dissolution and content uniformity during quality assurance. Detection of RAB was adequate at $280 \mathrm{~nm}$. The initial trial was conducted using HPLC and chromatographic separation was obtained on a Waters symmetry $\mathrm{C}_{18}$ column (150 x 4.6mm, particle size $5 \mu \mathrm{m})$. RAB is an acid labile compound and to avoid any degradation, a mobile phase with basic $\mathrm{pH}$ was selected. The mobile phase was optimized in the ratio of $10 \mathrm{mM}$ potassium dihydrogen phosphate buffer $(\mathrm{pH}$ 7.4, adjusted with potassium hydroxide solution) to acetonitrile of $65: 35(\mathrm{v} / \mathrm{v})$ with a flow rate of $1.0 \mathrm{ml} / \mathrm{min}$ and injection volume $20 \mu \mathrm{l}$.

While developing the UPLC method, basic chromatographic conditions such as the column, solvents and UV detection employed in the HPLC method were taken into account. In selecting the UPLC column, its stability at the higher $\mathrm{pH}$ was taken into consideration to preserve the long life of the column. For RAB, the recommended Food and Drug Administration (FDA) medium for dissolution solution studies is $\mathrm{pH} 8.0$; the optimized mobile phase $\mathrm{pH}$ used in the present study is also on the basic side. Most commercial $\mathrm{C}_{18}$ columns are not stable at high $\mathrm{pH}$ on the longer run, thus shortening their life span. Waters Acquity BEH $\mathrm{C}_{18}(50 \times 2.1 \mathrm{~mm}$, particle size $1.7 \mu \mathrm{m}$ ) column was found to be more suitable and stable at this $\mathrm{pH}$. The peak was sharp and acceptable and the injection volume was reduced from 20 to $5 \mu \mathrm{l}$. The flow rate also is scaled down from 1.0 to 0.4 $\mathrm{ml} / \mathrm{min}$. When these operating condition were applied to the developed method, a satisfactory peak was achieved for RAB, which eluted at around 1.49 min giving a total run time of 2 min.

A comparison of HPLC and UPLC (Fig 2) with regard to elution time, sensitivity and other chromatographic parameters when the standard solution was injected, is shown in Table 3.The results indicate that the elution 
time of RAB was reduced by about 9-fold compared to that for HPLC. Theoretical plates obtained for UPLC are about 8-fold higher than for HPLC which proves the higher separation efficiency of the UPLC than that of the HPLC method.
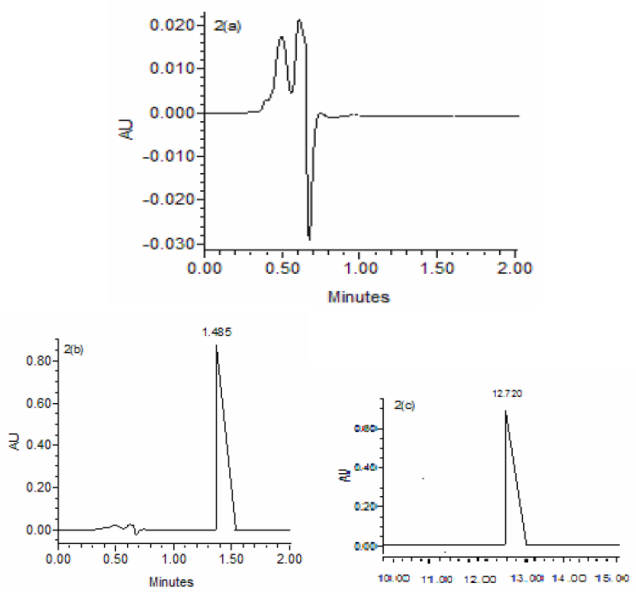

Fig 2: UPLC chromatograms of blank (a) and standard (b); also, HPLC chromatogram of standard (c)

Table 3: Comparative operating parameters of HPLC and developed UPLC methods

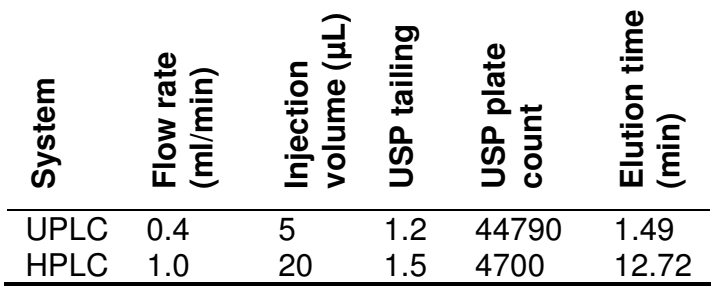

\section{CONCLUSION}

The new, isocratic RP-UPLC method proved to be simple, linear, precise, accurate, robust, rugged and rapid. The developed method was capable of giving faster elution, maintaining good separation more than that achieved with conventional HPLC. The short retention time of 1.49 min allows the analysis of a large number of samples in a short period of time and is therefore more costeffective for routine analysis in the pharmaceutical industries. The developed method was successfully applied to the dissolution study of RAB tablet. It is suitable for rapid and accurate quality control of $R A B$ in tablet formulations.

\section{ACKNOWLEDGEMENT}

The authors would like to thank Waters India Pvt Ltd for support with UPLC.

\section{REFERENCES}

1. Sweetman SC, Ed, In: Martindale: The Complete Drug Reference, 36 th Edn, Pharmaceutical Press, London, 2009; $p 1765$.

2. Garcia VC, Paim SC, Steppe M. New liquid chromatographic method for determination of rabeprazole sodium in coated tablets. JAOAC Int. 2004; 87: 842-846.

3. Uma Mahesh K, Sanjeeva Y. A simple and validated reverse phase HPLC method for the determination of rabeprazole in pharmaceutical dosage forms. E-J Chem. 2010; 7: 569-577.

4. Buchireddy $R$, Mukkanti $K$, Srinivasulu $P$, Srinivas $S V$. A validated stability-indicating $L C$ method for rabeprazole sodium. Chromatographia. 2008; 68: 275-280.

5. Battu PR, Reddy MS. Development and validation of RP-HPLC for the rabeprazole sodium in pharmaceutical formulations and human plasma. Asian J Research Chem. 2009; 2: 4951.

6. Shirkhedkar AA, Surana SJ. Application of stabilityindicating RP-TLC densitometric determination of rabeprazole sodium in bulk drug and pharmaceutical formulation. Eurasian J Anal Chem. 2009; 4: 87-97.

7. Rahman N, Bano Z, Najmul Hejaz Azmi S. Quantitative analysis of rabeprazole sodium in commercial dosage forms by spectrophotometry. Chem Pharm Bull. 2008; 56: 995-1001.

8. Madhuri $D$, Chandrasekhar $K B$, Ramakotaiah $M$, Somasekhar G, Harinadhababa K, Ravi Kumar K. Validation of spectrophotometric determination of rabeprazole using ferric chloride $\left(\mathrm{FeCl}_{3}\right)$. Int $\mathrm{J}$ Res Pharm Sci. 2010; 1: 209-211.

9. Mallikarjuna Gouda M, Somashekar S, Rajesh Kumar $P$, Shanta Kumar SM. Physicochemical characterization, UV spectrophotometric analytical method development and validation studies of rabeprazole sodium. J Chem Pharm Res. 2010; 2: 187-192. 
10. Radi A, Abd El-Ghany N, Wahdan T. Voltammetric behaviour of rabeprazole at a glassy carbon electrode and its determination in tablet dosage form. II Farmaco. 2004; 59: 515-518.

11. Masatomo M, Hitoshi T, Shigeru S, Tomonori $H$, Toshio S. Determination of rabeprazole enantiomers and metabolites by highperformance liquid chromatography with solidphase extraction. J Pharm Bio Anal. 2006; 41: 565-570.

12. Bhavesh HP, Bhanubhai NS, Madhabhai MP, Jignesh RP. High performance liquid chromatography and thin layer chromatography for the simultaneous qauntitation of rabeprazole and mosapride in pharmaceutical products. J Chrom Sci. 2008; 46: 10-14.

13. Shweta SS, Nilesh DD, Vijay YJ, Santosh VG. Spectrophotometric simultaneous determination of rabeprazole sodium and itopride hydrochloride in capsule dosage form. Mole Bio Spec. 2008; 69: 849-852.

14. Suganthi A, Sofiya J, Ravi TK. Simultaneous HPTLC determination of rabeprazole and itropride hydrochloride from their combined dosage form. Indian J Pharm Sci. 2008; 70: 366-368.

15. Shweta SS, Nilesh DD, Vijay $Y J$, Santosh RT, Santosh VG. Spectrophotometric simultaneous determination of rabeprazole sodium and domperidone in combined tablet dosage form. Eurasian J Anal Chem. 2008; 3: 236-244.

16. International Conference on Harmonization. ICH Harmonised Tripartite Guidelines-Validation of Analytical Procedures, 1997. 